\title{
Correction to: An emerging Al mainstream: deepening our comparisons of Al frameworks through rhetorical analysis
}

\author{
Epifanio Torres ${ }^{1} \cdot$ Will Penman ${ }^{2}$
}

Accepted: 2 December 2020

(c) The Author(s), under exclusive licence to Springer-Verlag London Ltd. part of Springer Nature 2021

\section{Correction to: AI \& SOCIETY}

$$
\text { https://doi.org/10.1007/s00146-020-01073-0 }
$$

The original version of this article has an error in the affiliations of one of the authors, Will Penman.

The correct affiliations for Will Penman.

Princeton Writing Program, New South 308, Princeton, NJ 08540

The original article has been corrected.

Publisher's Note Springer Nature remains neutral with regard to jurisdictional claims in published maps and institutional affiliations.

The original article can be found online at https://doi.org/10.1007/ s00146-020-01073-0.

Epifanio Torres

epifanio@princeton.edu

Will Penman

wpenman@princeton.edu

1 Department of Computer Science, Princeton University, 35

Olden St, Princeton, NJ 08540, USA

2 Princeton Writing Program, New South 308, Princeton, NJ 08540, USA 